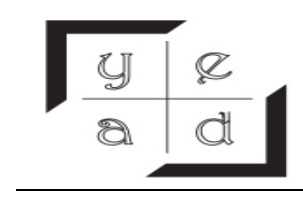

yönetim ve ekonomi arastırmaları dergुisi

journal of management and eeonomies researeh

Cilt/Volume: 19 Sayl/Issue: 4 Aralık/December 2021 ss. /pp. 404-418

E. Akdamar, M. Göğebakan http://dx.doi.org/10.11611/yead.996572

\title{
SUYOLU TAŞIMACILIĞI VE GEMICIILIKK SEKTÖRÜ İÇİN FİNANSAL ENDEKS
}

Dr. Öğr. Üyesi Emrah AKDAMAR *

\section{Dr. Öğr. Üyesi Maruf GÖGEBAKAN * iD}

\section{ÖZET}

İsletmelerin finansal performanslarının belirlenmesi ve karşılaştırılması küresel rekabet açısından önemli rol oynamaktadır. Finansal performansin ölçülmesi amacıyla çeşitli sektörlere ilişkin endeksler geliştirilmiştir. Bu çalışmada, suyolu taşımacılığı ve gemicilik sektörüne ilişkin finansal performansın ölçülmesine yönelik bir endeks oluşturulmuştur. Bu endeks, sektörde faaliyet gösteren 223 işletmenin 20 finansal oranı kullanılarak faktör analizi ve temel bileşenler analiziyle geliştirilmiştir. Elde edilen bulgulara göre 20 finansal oran 7 faktöre indirgenmiş ve toplam varyansin \%85'i bu faktörlerle açıklanmıştır. Varyans açılama oranı en yüksek olan iki faktörün karlılık ile ilgili oranlardan oluştuğu görülmüş̧ür. Bu iki faktör endeks skorunun \%48,43'ünü oluşturmaktadır. Buna bağlı olarak, bir işletmenin suyolu taşımacılığı ve gemicilik sektöründe finansal performans bakımından ön sıralarda yer alabilmesi için karlılık oranlarını iyileştirmesi gerektiği görülmüştür. Endeks skorları [0-1] normalleştirilen 223 işletmenin finansal performans ortalaması \%1,9 olarak gerçekleşmiştir. Bu sonuca göre sektördeki işletmelerin finansal performanslarının düşük olduğu, karlılık oranları noktasında iyi performans sergileyen işletmelerin aykırı değer olarak ayrıştığı görülmüş̧ür.

Anahtar kelimeler: Finansal endeks, Suyolu taşımacılı̆̆ı ve gemicilik sektörü, Faktör analizi, Temel bileșenler analizi

Jel Kodları: $C 10, C 38, F 65$

\section{FINANCIAL INDEX FOR WATER TRANSPORTATION AND SHIPPING INDUSTRY}

\begin{abstract}
Determining and comparing the financial performances of the enterprises plays an important role in terms of global competition. Indices for various sectors have been developed to measure financial performance. In this study, an index was created to measure the financial performance of the water transportation and shipping industry. This index was developed by factor analysis and principal component analysis using 20 financial ratios of 223 companies operating in the sector. According to the findings, 20 financial ratios were reduced to 7 factors and $85 \%$ of the total variance was explained
\end{abstract}

\footnotetext{
* Bandırma Onyedi Eylül Üniversitesi, Denizcilik Fakültesi, Denizcilik İşletmeleri Yönetimi Bölümü, Balıkesir/ Türkiye. Email: eakdamar@bandirma.edu.tr

* Bandırma Onyedi Eylül Üniversitesi, Denizcilik Fakültesi, Denizcilik İşletmeleri Yönetimi Bölümü, Balıkesir/ Türkiye, Email: mgogebakan@bandirma.edu.tr
}

\section{Makale Gecmisii/Article History}


by these factors. It was observed that the two factors with the highest variance explanation rate were the ratios related to profitability. These two factors make up 48,43\% of the index score. Accordingly, it has been seen that an enterprise needs to improve its profitability ratios in order to be at the forefront of financial performance in the water transportation and shipping industry. The average financial performance of 223 enterprises, whose index scores were normalized [0-1], was 1,9\%. According to this result, it has been observed that the financial performance of the enterprises in the sector is low, and the enterprises that perform well in terms of profitability ratios are differentiated as outliers.

Keywords: Financial index, Water transportation and shipping industry, Factor analysis, Principal component analysis

Jel Codes: $C 10, C 38, F 65$

\section{GİRIŞ}

Finansal oranlar bir işletmenin performansını ve finansal durumunu değerlendirmede önemli bir rol oynamaktadır. Yıllar içinde yapılan ampirik çalışmalar, finansal oranların takibinin işletmelerin mali açıdan öngörülebilirliğini arttırdığını göstermiştir (Chen ve Shimerda, 1981).

Finansal oranlar sağladıkları bilgi açısından karlılık oranları, likidite oranları, finansal kaldıraç oranları, verimlilik oranları gibi çeşitli kategorilere ayrılmaktadır. Her bir kategori altında çok sayıda finansal oran olduğundan, literatürde finansal oranları daha az sayıda faktörle açıklamaya çalışan çok sayıda çalışma bulunmaktadır (Erdogan, 2013).

$\mathrm{Bu}$ çalışmalarda faktör analizi (FA) ve temel bileşenler analizinin (TBA) sıklıkla kullanıldığı görülmektedir (Pinches, vd., 1973; Charbaji, 1994; De ve Bandyopadhyay, 2011; Öcal, vd., 2007). FA ve TBA, ölçülebilir ve gözlemlenebilir değişkenlerin, ortak bir varyansı paylaşan ve gözlemlenemeyen daha az sayıdaki gizil değişkene indirgenmesi prensibine dayalı çalışır. Bu gözlemlenemeyen faktörler, doğrudan ölçülemeyen ancak değişkenleri temsil etmek için kullanılan varsayımsal yapılardır (Yong ve Pearce, 2013). Elde edilen yeni gizil değişkenlerin (faktörlerin) toplam bilginin (değişkenliğin) ne kadarını açıkladığı, her bir faktörün bu açıklamada ne kadar etkili olduğu FA ve TBA ile belirlenir. Literatürde, FA ve TBA'nın bu özelliğine dayalı olarak çeşitli sektörlere ilişkin farklı konularda performans endeksleri oluşturulduğu görülmektedir.

$\mathrm{Bu}$ örneklerden ilki Dünya Bankası tarafından iki yılda bir yayınlanan Lojistik Performans Endeksi'dir (LPE). Bu endeks, sektörde faaliyet gösteren işletmelerin en çok ticari ilişkide bulundukları 8 ülkeye ilişkin değerlendirmelerinden hareketle oluşturulmuştur. Anket yoluyla çok sayıda değişkene ilişkin toplanan veriler, TBA ile analiz edilmekte ve çok sayıda girdi, altı ana bileşen (faktör) ile temsil edilmektedir. Daha sonra her bir faktör, TBA sonucu belirlenen ağırlı̆̆ı ölçüsünde endekste yer almıştır. Özetle LPE, çok sayıda girdinin bir boyut indirgeme yöntemi olan TBA ile altı ana bileşene indirgenmesiyle oluşturulan bir endekstir (Martí vd., 2017). Diğer bir çalışmada Işı̆̆ıçok (1999), 
Bursa'daki 100 büyük tekstil firmasına ilişkin 5 değişkeni 2 bileşene indirgemiş ve bileşenlerin analiz sonucu belirlenen ağırlıklarını kullanarak bir performans skoru elde etmiş ve firmaları bu skora göre sıralamıştır. Enerji göstergeleri üzerine bir çalışma gerçekleştiren Gökçe (2014), TBA kullanarak Türkiye ve Avrupa Birliği için enerji kırılganlık endeksi geliştirmiştir. TBA kullanılan başka bir çalışmada Servi ve Erişoğlu (2020), Türkiye'deki iller için gelişmişlik endeksi oluşturmuştur. Diğer bir çalışmada Hamamcı ve Şahinoğlu (2020), ülkelere ilişkin makroekonomik performans endeksini TBA kullanarak hesaplamıştır. Albayrak ve Erkut (2010), Türkiye'deki il ve bölgelere ilişkin bölgesel rekabet gücü endeksi oluşturmak amacıyla kullandığı 32 değişkeni 5 faktöre indirgemiş ve toplam varyansın $\% 88$ 'ini açıklamıştır.

Denizcilik sektörünün bir kolu olan suyolu taşımacıllğg ve gemicilik, küresel ticaretin önemli aktörlerinden biri olması nedeniyle küresel ekonominin bütünleyici bir parçasıdır. Bu bağlamda sektörde faaliyet gösteren işletmelerin finansal performanslarının belirlenmesi ve finansal durumlarının takip edilmesi işletmeler ve yatırımcılar açısından önem arz etmektedir (Corbett ve Winebrake, 2008). Literatürde denizcilik sektörüne ilişkin finansal performansı değerlendiren çeşitli çalışmalar bulunmaktadır (Andreou vd., 2014; Kang vd., 2016; Lee vd., 2012; Lee vd., 2014; Lee ve Lin, 2014; Pantouvakis ve Dimas, 2010; Syriopoulos ve Tsatsaronis, 2011).

$\mathrm{Bu}$ çalışmada literatürdeki çalışmalardan farklı olarak denizcilik işletmelerinin finansal performansının ölçülmesinde ilk defa faktör ağırlıkları kullanılarak endeks oluşturma yöntemi önerilmiştir. Bu amaçla, suyolu taşımacılı̆̆ 1 ve gemicilik sektöründe faaliyet gösteren 223 işletmenin 20 farklı finansal oranından hareketle FA ve TBA yöntemleri kullanılarak bir finansal endeks oluşturulmuştur.

\section{VERİ VE YÖNTEM}

\subsection{Veri}

Bu çalışmada Wall Street Journal (WSJ) tarafından Suyolu taşımacılığı ve gemicilik sektöründe faaliyet gösteren 223 işletme için toplanan 20 finansal oran kullanılmaktadır (WSJ, 2020). Elde edilen finansal oranlar WSJ tarafindan Tablo 1.'deki gibi kategorize edilmektedir. 
Tablo 1. Çalışmada Kullanılan Finansal Oranlar

\begin{tabular}{|c|c|}
\hline Kategori & Finansal Oranlar \\
\hline Değerleme (V) & $\begin{array}{ll}\text { 1. } & \text { Fiyat satış oranı (V1) } \\
\text { 2. } & \text { Fiyat defter değeri oranı (V2) } \\
\text { 3. } & \text { Kurumsal değer FAVÖK oranı (V3) } \\
\text { 4. } & \text { Kurumsal değer satı̧ oranı (V4) }\end{array}$ \\
\hline Likidite (L) & $\begin{array}{ll}\text { 1. } & \text { Cari oran (L1) } \\
\text { 2. } & \text { Likidite oran1 (L2) } \\
\text { 3. } & \text { Nakit oran (L3) }\end{array}$ \\
\hline Karlılık (P) & $\begin{array}{ll}\text { 1. } & \text { Brüt kar oranı (P1) } \\
\text { 2. } & \text { Faaliyet karı (P2) } \\
\text { 3. } & \text { Vergi öncesi karı (P3) } \\
\text { 4. } & \text { Net kar (P4) } \\
\text { 5. } & \text { Aktif karlılık (P5) } \\
\text { 6. } & \text { Toplam sermaye getirisi (P6) }\end{array}$ \\
\hline Sermaye Yapısı (CS) & $\begin{array}{ll}\text { 1. } & \text { Toplam borç öz sermaye oranı (CS1) } \\
\text { 2. } & \text { Toplam borç toplam sermaye oran1 (CS2) } \\
\text { 3. } & \text { Toplam borç toplam varlık oranı (CS3) } \\
\text { 4. } & \text { Faiz karş1lama oranı (CS4) } \\
\text { 5. } & \text { Uzun vadeli borçların öz sermayeye oranı (CS5) } \\
\text { 6. } & \text { Uzun vadeli borçların toplam sermayeye oran1 (CS6) } \\
\text { 7. } & \text { Uzun vadeli borçların varlıklara oranı (CS7) }\end{array}$ \\
\hline
\end{tabular}

\subsection{Faktör Analizi}

Faktör analizi, ölçülebilen ve hesaplanabilen çok sayıdaki değişkenin arkasındaki farklılıkları ve bu farlılıklara neden olan özellikleri, yani hesaplanamayan ve ölçülemeyen gizil boyutları ortaya çıkarmaya yarayan istatistiksel bir analizdir (Johnson ve Wichern, 2002). Faktör analizi, kullanılan değişkenlerin özellikleri bakımından birkaç grup olarak ifade edilebileceği durumlarda kullanılır. Faktör analizinde aralarında ilişki bulunan değişkenler bir grup olarak belirlenir ve bu yeni gruba faktör adı verilir. Çok değişkenli bir veride $\mathrm{p}$ adet değişken $\mathrm{k}$ adet faktör ile $(\mathrm{k}<\mathrm{p})$ açıklanmaya çalış1ır. Buradaki amaç, birbirleriyle yakın ilişkide olan değişkenleri aynı faktör altında toplamak ve mümkün olduğunca ilişkisiz faktörler elde etmektir. Kısaca faktör analizi; aralarında ilişki bulunan çok sayıdaki değişkeni bir faktöre atayarak, az sayıdaki anlamlı ve bağımsız faktörler şeklinde ifade eden, böylece boyut indirgeme ve sınıflandırma yapan çok değişkenli istatistiksel bir analizdir.

$X, n x p$ tipinde, $n$ adet suyolu taşımacılı̆ğ ve gemicilik sektöründe faaliyet gösteren işletme ve $p$ değişkenden oluşan veri matrisi olmak üzere,

$$
X_{n x p}=\left[\begin{array}{ccc}
X_{11} & \cdots & X_{1 p} \\
\vdots & \ddots & \vdots \\
X_{n 1} & \cdots & X_{n p}
\end{array}\right] \text { şeklinde gösterilir. } i=1, \ldots, n \text { ve } j=1, \ldots, p \text { olmak üzere } X_{i j} ; i \text {. işletmenin }
$$

j. değişkenine ait gözlemi ifade eder. Ortalama vektörü, standart sapma ve varyans kullanılarak gözlemler standartlaştırılır. Korelasyon matrisi ve bu matris kullanılarak da faktörlerden oluşan üretilmiş matris elde edilir. $\bar{X}_{i}=\frac{\sum_{i=1}^{n} X_{i j}}{n}$ ortalama vektörünü göstermek üzere, $s_{i}^{2}=\frac{\sum_{i=1}^{n}\left(X_{i j}-\bar{X}_{i}\right)^{2}}{n-1}$ 
varyansını gösterir. Veri matrisinde $i$. ve $k$. değişkenler arasındaki kovaryans ise $s_{i k}=\frac{\sum_{i=1}^{n} X_{i j} X_{k i}}{n-1}$ olacak şekildedir $(i, k=1, \ldots, p)$. Veri matrisindeki her bir gözlemin standart değeri, $z_{i j}=\frac{X_{i j}-\bar{X}_{i}}{s_{i}}$ olarak elde edilir. Burada $z_{i j},(i=1, \ldots, p)$ kümesinde $z_{i}$ değişkeni, ortalama vektörü 0 ve varyansı 1 olan standart değişkendir.

Değişkenlerin ölçü birimlerinin ve varyanslarının farklı olması faktörlerin belirlenmesinde önemli etkiye sahiptir. Ölçülen değerler yakın ise varyans-kovaryans matrisi, eğer ölçülen değerler birbirinden çok farklı ise korelasyon matrisi kullanılır. Bu nedenle, standartlaştırılmış veri matrisinin kullanılması doğru faktörlerin belirlenmesinde etkilidir. Standartlaştırılmış veri matrisinde varyanskovaryans ve korelasyon matrisleri eşittir (Özdamar, 2002). nxp tipindeki standartlaştırılmış veri matrisi $z_{i j}$ standartlaştırılmış gözlem değerlerinden oluşmak üzere,

$Z_{n x p}=\left[\begin{array}{ccc}Z_{11} & \cdots & z_{1 p} \\ \vdots & \ddots & \vdots \\ z_{n 1} & \cdots & z_{n p}\end{array}\right]$ şeklinde gösterilir. Standartlaştırılmış veri matrisi kullanılarak $n x n$ tipindeki korelasyon matrisi, $R_{n x n}=\frac{Z_{n x p} Z^{\prime}{ }_{p x n}}{n-1}$ şeklinde standartlaştırılmış veri matrisi ve bu matrisin transpozunun çarpımından elde edilir.

Faktör analizinde değişkenlerin atandığ faktörlerin her birinin farklı yükleri bulunmaktadır. Gözlemlerden oluşan veri matrisinden elde edilen $n x n$ tipindeki korelasyon matrisinde $|R-\lambda I|=0$ eşitliğindeki $p$. dereceden polinom çözüldüğünde, bu polinomun kökleri bize faktör analizinde kullanılan $\lambda_{i}$ özdeğerlerini ve bunlara karşılık gelen $c_{i}$ öz vektörlerini vermektedir. Bu özdeğer ve öz vektörlerden elde edilen faktör yükleri $e_{i j}=c_{i j} \sqrt{\lambda_{i}}$ denkleminden elde edilir. Burada $e_{i j}$, j. değişkenin $i$. faktör üzerindeki yükünü göstermektedir.

İşletmelerin performansının belirlenmesi ve karşılaştırılmasında çok değişkenli veriler üzerinde faktör analizi yapmak için çok faktörlü model uygulanmıştır. Çok faktörlü model, $m>2$ faktör sayısı olmak üzere,

$$
\begin{gathered}
x_{1}=e_{11} z_{1}+e_{12} z_{2}+\cdots+e_{1 m} z_{m}+\varepsilon_{1} \\
x_{2}=e_{21} z_{1}+e_{22} z_{2}+\cdots+e_{2 m} z_{m}+\varepsilon_{2} \\
\vdots \\
x_{p}=e_{p 1} z_{1}+e_{p 2} z_{2}+\cdots+e_{p m} z_{m}+\varepsilon_{p}
\end{gathered}
$$

denklemlerinden oluşur. Burada $e_{i j}$ faktör ağırlıklarını, $z_{i}$ türetilmiş faktörleri, $x_{i}$ gösterge değerlerini ve $\varepsilon_{i}$ özel faktörleri temsil etmektedir (Tabachnick vd., 2007). 
Yeniden üretilmiş korelasyon matrisi simetrik olmayan bir matris olmakla beraber üst üçgensel elemanları yeniden türetilmiş korelasyon rezidülerini, alt üçgensel elemanları yeniden türetilmiş korelasyon matrisini ve köşegen elemanları ise ortak faktör varyanslarını temsil etmektedir.

\subsubsection{Temel Bileşenler Analizi}

FA ve TBA birbirini destekleyen iki istatistiksel analiz yöntemidir. Kısaca FA, TBA'nın bir genellemesi olarak görülmektedir ve kovaryans matrisi ya da korelasyon matrisinden yararlanılarak hesaplanır. Her iki yöntemde de veride boyut indirgeme söz konusudur (Özdamar ve Dinçer, 1987).

TBA kısaca, bütün değiş̧kenlerdeki maksimum varyansı açıklayacak faktörün bulunması yöntemi olarak açıklanabilir. Faktör sayısının değişken sayısına eşit olması durumunun önüne geçmek için özdeğer istatistiği kullanılarak analizlerde kaç faktör kullanılacağına karar verilir (Özdamar, 2004).

\section{BULGULAR}

Suyolu taşımacıllğ 1 ve gemicilik sektöründe faaliyet gösteren 223 adet denizcilik işletmesine ait, Değerleme (V), Likidite (L), Karlılık (P) ve Sermaye Yapısı (CS) olmak üzere dört temel başlık altında bulunan 20 adet finansal oran faktör analizi ile incelenmiştir. Önerilen yöntem ile 20 adet finansal oranı belirli faktör gruplarına atayarak az sayıda değişken ile temsil etmek ve temel bileşenler yöntemi sonucu elde edilen özdeğerlerden hareketle her bir faktörün endeksteki ağırlığını belirlemektir. Temel bileşenler yöntemi ile gerçekleştirilen faktör analizinde, faktörler arasında bir ilişki beklendiği için Direct Oblimin döndürme algoritması kullanılmıştır. Analizde kullanılan verilerin faktör analizine uygun olup olmadığını belirlemek amacıyla, KaiserMeyer-Olkin (KMO) ve Bartlett uygunluk testlerine bakılmıştır. KMO değeri, 0,658 ve Bartlett testi sonucu elde edilen Ki-kare istatistiği 5972,374 bulunmuştur $(\mathrm{p}<0,000)$. Bu bulgular, verilerin faktör analizine uygun olduğunu göstermektedir. Direct Oblimin döndürme yöntemiyle elde edilen bulgulara göre 20 adet finansal oran 7 faktör altında toplanmaktadır. Elde edilen döndürülmüş faktör matrisi Tablo 2.'de görülmektedir. 
Tablo 2. Döndürülmüş Faktör Matrisi

\begin{tabular}{|l|c|c|c|c|c|c|c|}
\hline & \multicolumn{7}{|c|}{ Faktörler } \\
\cline { 2 - 8 } & 1 & 2 & 3 & 4 & 5 & 6 & 7 \\
\hline P3 &, 971 & & & & & & \\
\hline P4 &, 947 & & & & & & \\
\hline P5 &, 947 & & & & & & \\
\hline P1 & &,- 904 & & & & & \\
\hline P6 & &,- 822 & & & & & \\
\hline P2 & &,- 777 & & & & & \\
\hline CS1 & & &, 997 & & & & \\
\hline V2 & & &, 997 & & & & \\
\hline CS5 & & &, 946 & & & & \\
\hline CS7 & & & &, 936 & & & \\
\hline CS3 & & & &, 876 & & & \\
\hline CS2 & & & &, 783 & & & \\
\hline CS6 & & & &, 683 & & & \\
\hline L2 & & & & &,- 977 & & \\
\hline L1 & & & & &,- 954 & & \\
\hline L3 & & & & &,- 934 & & \\
\hline V1 & & & & & &, 923 & \\
\hline V4 & & & & & &, 885 & \\
\hline V3 & & & & & & &, 853 \\
\hline CS4 & & & & & & &,- 558 \\
\hline Indirgeme Yöntemi: Temel Bileşenler Analizi. \\
Döndürme Yöntemi: Oblimin-Kaiser Normalleştirmesi. \\
\hline
\end{tabular}

Döndürülmüş faktör matrisi incelendiğinde, Karlılık (P) başlığındaki P3, P4 ve P5 oranının birinci faktörde ve P1, P6 ve P2 oranının ikinci faktörde toplandığı görülmektedir. Üçüncü faktörde, Sermaye Yapısı (CS) oranlarından CS1 ve CS5 ile Değerleme (V) oranlarından V2 bulunmaktadır. Dördüncü faktör ise; CS7, CS3, CS2 ve CS6 olmak üzere Sermaye Yapısı başlığındaki dört orandan oluşmaktadır. Likidite (L) başlığı altında incelenen üç oran beşinci faktörü oluşturmaktadır. Altıncı faktörü, Değerleme (V) oranlarından V1 ve V4; yedinci faktörü ise V3 ve CS4 oluşturmaktadır. Elde edilen 7 faktörün özdeğerleri ve varyans açılama oranları Tablo 3.'de verilmiştir.

Tablo 3. Faktörlerin Varyans Açıklama Oranları

\begin{tabular}{|l|r|r|r|r|r|r|}
\hline \multicolumn{7}{|c|}{ Açılanan Toplam Varyans } \\
\hline \multirow{2}{*}{ Faktörler } & \multicolumn{7}{|c|}{ Özdeğerler } & & \multicolumn{3}{c|}{ İndirgenen özdeğerler } \\
\cline { 2 - 7 } & & Varyans \% & Kümülatif Varyans \% & & Varyans \% & Kümülatif Varyans \% \\
\hline 1 & 5,157 & 25,787 & 25,787 & 5,157 & 25,787 & 25,787 \\
\hline 2 & 3,082 & 15,411 & 41,199 & 3,082 & 15,411 & 41,199 \\
\hline 3 & 2,513 & 12,567 & 53,766 & 2,513 & 12,567 & 53,766 \\
\hline 4 & 2,149 & 10,746 & 64,511 & 2,149 & 10,746 & 64,511 \\
\hline 5 & 1,836 & 9,179 & 73,691 & 1,836 & 9,179 & 73,691 \\
\hline 6 & 1,216 & 6,080 & 79,771 & 1,216 & 6,080 & 79,771 \\
\hline 7 & 1,059 & 5,297 & 85,068 & 1,059 & 5,297 & $\mathbf{8 5 , 0 6 8}$ \\
\hline 8 &, 920 & 4,598 & 89,666 & & & \\
\hline 9 &, 678 & 3,391 & 93,057 & & & \\
\hline
\end{tabular}

Elde edilen bulgulara göre; 20 finansal oranın indirgenmiş 7 faktör ile yaklaşık $\% 85^{\prime} \mathrm{i}$ açıklanmaktadır. Temel bileşenler yöntemi ile elde edilen özdeğerlerden hareketle her bir faktörün endeksteki ağırlığını $\left(w_{i}\right)$ belirlemek amacıyla, 


$$
w_{i}=\frac{\lambda_{i}}{\sum \lambda_{i}} \quad \mathrm{i}=1,2, \ldots, 7
$$

eşitliğinden yararlanılmıştır. Burada $\lambda_{i}$ öz değerlerinden yararlanarak her bir faktörün endeks ağırlığ aşağıdaki gibi hesaplanmıştır:

$$
\begin{aligned}
& w_{1}=\frac{\lambda_{1}}{\sum \lambda_{i}}=\frac{5,157}{5,157+3,082+2,513+2,149+1,836+1,216+1,059}=\frac{5,157}{17,012}=0,3031 \\
& w_{2}=\frac{\lambda_{1}}{\sum \lambda_{i}}=\frac{3,082}{17,012}=0,1812 \\
& w_{3}=\frac{\lambda_{1}}{\sum \lambda_{i}}=\frac{2,513}{17,012}=0,1477 \\
& w_{4}=\frac{\lambda_{1}}{\sum \lambda_{i}}=\frac{2,149}{17,012}=0,1263 \\
& w_{5}=\frac{\lambda_{1}}{\sum \lambda_{i}}=\frac{1,836}{17,012}=0,1079 \\
& w_{6}=\frac{\lambda_{1}}{\sum \lambda_{i}}=\frac{1,216}{17,012}=0,0715 \\
& w_{7}=\frac{\lambda_{1}}{\sum \lambda_{i}}=\frac{1,059}{17,012}=0,0622
\end{aligned}
$$

Hesaplanan ağırlıklardan hareketle Tablo 4.'de, her bir faktör adlandırılmış ve faktörlerin endeks içerisindeki ağırlığı yüzde cinsinden gösterilmiştir. Buna göre, işletmelerin suyolu taşımacılığı ve gemicilik sektörüne ilişkin finansal performansının en önemli belirleyicilerinin karlılık ile ilgili faktörler olduğu görülmüştür. İşletmelerin toplam endeks skorunun 30,31\%’ini “Varlıklar ve karlılık faktörü” ve 18,12\%'sini “Toplam sermaye ve karlılık faktörü” oluşturmaktadır. Başka bir deyişle, sektörde faaliyet gösteren işletmelerin finansal performanslarının yaklaşık yarısı $(48,43 \%)$ karlılık oranlarına bağlıdır. 
Yönetim ve Ekonomi Araștırmalarl Dergisi / Journal of Management and Economics Research

Cilt/Volume: 19 Sayl/Issue: 4 Arallk/December 2021 ss. /pp. 404-418

E. Akdamar, M. Göğebakan http://dx.doi.org/10.11611/yead.996572

Tablo 4. Faktörlerin Adlandırılması ve Endeks İçerisindeki Ağırlıkları

\begin{tabular}{|c|c|c|c|}
\hline Faktör & Faktördeki finansal oranlar & $\begin{array}{l}\text { Faktörün } \\
\text { adlandırılması }\end{array}$ & $\begin{array}{l}\text { Endeksteki } \\
\text { ağırlıkları }\end{array}$ \\
\hline Faktör 1 & $\begin{array}{l}\text { Vergi öncesi karı (P3) } \\
\text { Net kar (P4) } \\
\text { Aktif karlılık (P5) }\end{array}$ & $\begin{array}{l}\text { Varlıklar ve } \\
\text { karlılık faktörü }\end{array}$ & $30,31 \%$ \\
\hline Faktör 2 & $\begin{array}{l}\text { Brüt kar oranı }(\mathrm{P} 1) \\
\text { Toplam sermaye getirisi }(\mathrm{P} 6) \\
\text { Faaliyet karı }(\mathrm{P} 2)\end{array}$ & $\begin{array}{l}\text { Toplam sermaye } \\
\text { ve karlılık } \\
\text { faktörü }\end{array}$ & $18,12 \%$ \\
\hline Faktör 3 & $\begin{array}{l}\text { Toplam borç öz sermaye oranı (CS1) } \\
\text { Fiyat defter değeri oranı (V2) } \\
\text { Uzun vadeli borçların öz sermayeye } \\
\text { oranı (CS5) }\end{array}$ & $\begin{array}{l}\text { Öz sermaye ve } \\
\text { borç faktörü }\end{array}$ & $14,77 \%$ \\
\hline Faktör 4 & $\begin{array}{l}\text { Uzun vadeli borçların varlıklara oranı } \\
\text { (CS7) } \\
\text { Toplam borç toplam varlık oranı (CS3) } \\
\text { Toplam borç toplam sermaye oranı } \\
\text { (CS2) } \\
\text { Uzun vadeli borçların toplam } \\
\text { sermayeye oranı (CS6) }\end{array}$ & $\begin{array}{l}\text { Varlık ve } \\
\text { sermaye faktörü }\end{array}$ & $12,63 \%$ \\
\hline Faktör 5 & $\begin{array}{l}\text { Likidite oran1 (L2) } \\
\text { Cari oran (L1) } \\
\text { Nakit oran (L3) }\end{array}$ & $\begin{array}{l}\text { Çalışma } \\
\text { sermayesi } \\
\text { faktörü }\end{array}$ & $10,79 \%$ \\
\hline Faktör 6 & $\begin{array}{l}\text { Fiyat satış oranı (V1) } \\
\text { Kurumsal değer satıș oranı (V4) }\end{array}$ & $\begin{array}{l}\text { Satış-gelir } \\
\text { faktörü }\end{array}$ & $7,15 \%$ \\
\hline Faktör 7 & $\begin{array}{l}\text { Kurumsal değer FAVÖK oranı (V3) } \\
\text { Faiz karş1lama oranı (CS4) }\end{array}$ & Harcama faktörü & $6,22 \%$ \\
\hline
\end{tabular}

$\mathrm{Bu}$ endeks hesaplama modeline göre;

$$
F I=\sum w_{i} F_{i}, \quad i=1,2, \ldots, 7
$$

olacak şekilde endeks ağırlığı $\left(w_{i}\right)$ ve faktör değerlerinin $\left(F_{i}\right)$ çarpımından elde edilmektedir. Ele alınan 223 işletmenin finansal endeksi (3) kullanılarak aşağıdaki şekilde hesaplanmaktadır.

Finansal Endeks $=0,3031 \mathrm{~F}_{1}+0,1812 \mathrm{~F}_{2}+0,1477 \mathrm{~F}_{3}+0,1263 \mathrm{~F}_{4}+0,1079 \mathrm{~F}_{5}+0,0715 \mathrm{~F}_{6}+0,0622 \mathrm{~F}_{7}$

Faktörlerin endeksteki ağırlıklarının elde edilmesinden sonra, her bir faktörü oluşturan finansal oranların faktör içindeki ağırlıkları Tablo 5.'de gösterilmiştir. 
Yönetim ve Ekonomi Araștırmalarl Dergisi / Journal of Management and Economics Research Cilt/Volume: 19 Sayl/Issue: 4 Arallk/December 2021 ss. /pp. 404-418

E. Akdamar, M. Göğebakan http://dx.doi.org/10.11611/yead.996572

Tablo 5. Finansal Oranların Faktörler Üzerindeki Ağırlıkları

\begin{tabular}{|l|c|c|c|c|c|c|c|}
\hline \multirow{2}{*}{ Finansal oranlar } & \multicolumn{9}{|c|}{ Faktörler } \\
\cline { 2 - 8 } & $\mathbf{1}$ & $\mathbf{2}$ & $\mathbf{3}$ & $\mathbf{4}$ & $\mathbf{5}$ & $\mathbf{6}$ & $\mathbf{7}$ \\
\hline V1 &, 014 &,- 059 &, 008 &, 010 &,- 011 & $\mathbf{, 5 0 5}$ &, 101 \\
\hline V2 &, 004 &,- 028 & $\mathbf{, 3 4 2}$ &,- 048 &, 002 &, 016 &,- 004 \\
\hline V3 &, 011 &,- 071 &, 001 &, 019 &, 006 &, 060 & $\mathbf{, 7 6 9}$ \\
\hline V4 &,- 022 &,- 023 &,- 009 &, 048 &, 007 & $\mathbf{, 4 8 7}$ &,- 117 \\
\hline L1 &,- 022 &, 002 &,- 001 &,- 006 & $\mathbf{- , 3 3 5}$ &,- 011 &, 009 \\
\hline L2 &,- 016 &, 001 &, 001 &, 012 & $\mathbf{- , 3 4 5}$ &, 000 &, 017 \\
\hline L3 &, 023 &,- 001 &, 004 &, 071 & $\mathbf{- , 3 3 4}$ &, 013 &,- 035 \\
\hline P1 &,- 012 & $\mathbf{- , 4 0 0}$ &, 018 &, 038 &, 000 &, 029 &, 040 \\
\hline P2 &,- 011 & $\mathbf{- , 3 2 3}$ &,- 010 &, 049 &,- 012 &,- 139 &, 051 \\
\hline P3 & $\mathbf{, 3 5 0}$ &, 036 &, 002 &, 025 &,- 007 &,- 008 &,- 020 \\
\hline P4 & $\mathbf{, 3 4 1}$ &, 022 &, 004 &, 021 &,- 008 &, 039 &, 028 \\
\hline P5 & $\mathbf{3 4 5}$ &,- 068 &,- 003 &,- 022 &, 030 &,- 056 &,- 016 \\
\hline P7 &, 032 & $\mathbf{- , 3 8 0}$ &,- 011 &,- 045 &, 007 &, 108 &,- 136 \\
\hline CS1 &,- 002 &, 001 & $\mathbf{3 4 1}$ &,- 035 &,- 003 &,- 007 &,- 003 \\
\hline CS2 &, 001 &, 058 &, 045 & $\mathbf{2 6 3}$ &, 065 &,- 060 &, 003 \\
\hline CS3 &, 005 &, 026 &, 020 & $\mathbf{3 0 1}$ &, 033 &,- 020 &,- 008 \\
\hline CS4 &, 020 &,- 133 &, 001 &, 003 &, 004 &, 092 & $\mathbf{- , 5 1 9}$ \\
\hline CS5 &, 002 &, 006 & $\mathbf{, 3 2 1}$ &, 053 &,- 005 &,- 004 &, 010 \\
\hline CS6 &, 007 &,- 054 &,- 021 & $\mathbf{2 4 8}$ &,- 049 &, 080 &, 038 \\
\hline CS7 &,- 008 &,- 004 &,- 042 & $\mathbf{, 3 3 3}$ &,- 052 &, 025 &,- 027 \\
\hline
\end{tabular}

Tablo 5.'de görüldügü gibi her bir faktör için en yüksek ağırlıklar, o faktörü oluşturan finansal oranlara aittir. İşletmelerin finansal oranları, faktörler üzerindeki ağırlıkları kullanılarak aşağıdaki gibi modellenir:

$$
F I=\sum w_{i}\left(a_{k} X_{k}\right), i=1,2, \ldots, 7 \text { ve } k=1,2, \ldots, 20
$$

Burada $a_{k}$, finansal oranın faktör üzerindeki ağırlığını, $X_{k}$ ise değişken grubundaki finansal oranı temsil etmektedir. Buna göre finansal endeks modeli Tablo 6.' daki gibi elde edilmiştir.

Tablo 6. Finansal Endeksin Hesaplanması

\begin{tabular}{|l|l|}
\hline FI & Faktör skorları \\
\hline $0,3031 *(0,350 * \mathrm{P} 3+0,341 * \mathrm{P} 4+0,345 * \mathrm{P} 5)$ & Varlıklar ve karlllık faktör skoru \\
\hline $0,1812 *(-0,400 * \mathrm{P} 1-0,323 * \mathrm{P} 2-0,380 * \mathrm{P} 7)$ & Toplam sermaye ve karlılık faktör skoru \\
\hline $0,1477 *(0,342 * \mathrm{~V} 2+0,341 * \mathrm{CS} 1+0,321 * \mathrm{CS} 5)$ & Öz sermaye ve borç faktör skoru \\
\hline $0,1263 *(0,263 * \mathrm{CS} 2+0,301 * \mathrm{CS} 3+0,248 * \mathrm{CS} 6+0,333 * \mathrm{CS} 7)$ & Varlık ve sermaye faktör skoru \\
\hline $0,1079 *(-0,335 * \mathrm{~L} 1-0,345 * \mathrm{~L} 2-0,334 * \mathrm{~L} 3)$ & Çalışma sermayesi faktör skoru \\
\hline $0,0715 *(0,505 * \mathrm{~V} 1+0,487 * \mathrm{~V} 4)$ & Satıs-gelir faktör skoru \\
\hline $0,0622 *(0,769 * \mathrm{~V} 3-0,519 * \mathrm{CS} 4)$ & Harcama faktör skoru \\
\hline TOPLAM & FiNANSAL ENDEKS SKORU \\
\hline
\end{tabular}

Tablo 6.'deki modelden hareketle 223 işletmenin finansal endeks skorları hesaplanmıştır. İşletmelerin finansal endeks skoruna ilişkin betimsel istatistikleri Tablo 7.'de verilmiştir. 
Tablo 7. İşletmelerin Finansal Endeks Skoruna İlişkin Betimsel İstatistikleri

\begin{tabular}{|l|l|}
\hline $\mathrm{N}$ & 223 \\
\hline En küçük & $-25,43$ \\
\hline En büyük & 2875,57 \\
\hline Ortalama & 30,67 \\
\hline Standart Sapma & 192,71 \\
Medyan & 12,25 \\
1. Kartil & 6,39 \\
3. Kartil & 20,05 \\
\hline
\end{tabular}

Betimsel istatistikler, suyolu taşımacıllğ̆ ve gemicilik sektöründe faaliyet gösteren işletmelerin finansal performansının değişkenliğinin oldukça yüksek olduğunu göstermektedir. Ancak, bu değişkenlik maksimum ve minimum skorlu işletmelerin aykırı değer olmasından kaynaklanmaktadır. İşletmelerin endeks skorları ile konumlarını belirleyebilmeleri ve finansal performanslarını karşılaştırmaları için endeks skorları [0-1] normalizasyonu ile yeniden hesaplanmıştır. Buna göre, işletmelerin endeks skorlarının [0-1] arasında değişen normalleştirilmiş değerleri aşağıdaki şekilde elde edilir.

$$
z_{i}=\frac{X_{i}-X_{\min }}{X_{\max }-X_{\min }}, i=1,2, \ldots, 223
$$

Burada $X_{\min }$ en düşük endeks skorunu, $X_{\max }$ ise en yüksek endeks skorunu göstermektedir. Tablo 8.'de işletmelerin normalleştirilmiş finansal endeks skorlarına ilişkin hesaplanan betimsel bulgular verilmiştir.

\section{Tablo 8. İşletmelerin Normalleştirilmiş Finansal Endeks Skoruna İlişkin Betimsel İstatistikleri}

\begin{tabular}{|l|l|}
\hline $\mathrm{N}$ & 223 \\
\hline En küçük & 0 \\
\hline En büyük & 1 \\
\hline Ortalama & 0,0193 \\
\hline Std. Sapma & 0,0664 \\
Medyan & 0,0130 \\
1. Kartil & 0,0110 \\
3. Kartil & 0,0157 \\
\hline
\end{tabular}

Endeks skoru en düşük olan işletmenin 0 olduğu baz alındığında ortalamanın 0,0193 olması 223 işletmenin genel finansal performansının düşük olduğuna işaret etmektedir. Nitekim 3. Kartil değerinin 0,0157 olması, işletmelerin 75\%'inin bu değerin altında kaldığını göstermektedir. Endeks hesaplama modelindeki ağırlığı düşünüldüğünde finansal performansı en iyi olan işletmelerin karlılık ile ilgili göstergelerinin olumlu olduğu söylenebilir. Başka bir deyişle, suyolu taşımacıllı̆ı ve gemicilik sektöründe faaliyet gösteren bir işletmenin finansal açıdan sektördeki rakiplerinden pozitif ayrışması için endeks ağırlığı en yüksek olan karlılık faktörlerini iyileştirmeye yönelmesi önerilmektedir.

\section{SONUÇ}

Bu çalışmada, suyolu taşımacılığı ve gemicilik sektöründe faaliyet gösteren işletmelerin finansal performanslarını ölçmek ve karşılaştırmak amacıyla, yeni bir finansal endeks oluşturulmuştur. $\mathrm{Bu}$ 
amaçla sektörde faaliyet gösteren 223 işletmenin 20 farklı finansal oranı kullanılarak faktör analizi yardımıyla finansal endeks modeli geliştirilmiştir. Bu model, birbirleriyle ilişkili değişkenleri aynı faktör altında toplayarak, her bir faktörün endeksteki ağıllı̆ıını hesaplamakta ve her bir finansal oranın ilgili faktördeki ağırlığını ayrı ayrı elde etmektedir.

Faktör analizi sonucunda, işletmelere ilişkin elde edilen 20 farklı finansal oranın 7 faktör altında toplandığı görülmüştür. $\mathrm{Bu}$ faktörlerin endeksteki ağırlığını belirlemek için gerçekleştirilen TBA sonucunda, 7 faktörün toplam değişkenliğin yaklaşık 85\%'ini açıkladığı belirlenmiştir. Diğer taraftan, indirgenmiş 7 faktör arasında endeksteki ağırlığı en yüksek olan ilk iki faktör 30,31\% ile "Varlıklar ve karlıl1k faktörü” ve 18,12\% ile “Toplam sermaye ve karlılık” faktörüdür. Başka bir deyişle, karlılık ile ilgili oranların suyolu taşımacılığı ve gemicilik sektöründe finansal performansı önemli ölçüde belirlediği söylenebilir.

Finansal performansı karlılık faktörlerinden sonra en çok etkileyen faktörler sermaye yapısı ile ilgili faktörlerdir. Finansal performans üzerinde "Öz sermaye ve borç faktörü” 14,77\% ve "Varlık ve sermaye faktörü" $12,63 \%$ oranında etkilidir. Bu faktörleri sırasıyla 10,79\% ile "Çalışma sermayesi faktörü”, 7,15\% ile "Satış-gelir faktörü” ve 6,22\% ile "Harcama faktörü” takip etmektedir.

İndirgenmiş 7 faktör ile oluşturulan finansal endeks modelinde her bir faktör, endeksteki ağırlığı ile temsil edilmektedir. Ayrıca, faktörleri oluşturan her bir finansal oranın ağırlığı da endeks ağırlığını etkilemektedir. Bu bağlamda bulgular değerlendirildiğinde, "Toplam sermaye ve karlılık faktörü" ile “Çalışma sermayesi faktörü” nün finansal endeks skorlarını negatif yönde etkilediği görülmüştür.

Her bir işletmenin finansal endeks skoru hesaplandığında, bazı işletmelerin aykırı değer olarak ayrıştığı belirlenmiştir. İşletmeleri karşılaştırma ve yorumlama kolaylığı için finansal endeks skorlarına [0-1] normalizasyonu uygulanmıştır. Dolayısıyla işletmeler finansal skorlarını 100 puan üzerinden değerlendirebilmektedir. Ele alınan 223 işletmenin finansal performans ortalamasının 1,9\% olduğu görülmüştür. En düşük skora sahip işletmenin 0 puan aldığ 1 düşünüldüğünde suyolu taşımacıllğ̆ ve gemicilik endüstrisinin finansal performansı oldukça düşüktür.

Sektörde faaliyet gösteren işletmelerin finansal performans bakımından olumlu anlamda ayrışması öncelikle karlılık oranlarındaki iyileşmeye bağlıdır. İşletmeler daha sonra sırasıyla sermaye yapısı, likidite ve değer ile ilgili finansal oranlara önem vermelidir. Oluşturulan bu endeks, sektörde faaliyet gösteren işletmelerin, kendi finansal konumlarını görebilmesi ve gelişmeye açık yanlarını belirleyebilmesi açısından önem arz etmektedir.

\section{KAYNAKÇA}

Albayrak, A. N., \& Erkut, G. (2010). Türkiye'de il ve bölgelerin rekabet gücü analizi. itüdergisi/a mimarlık, planlama, tasarım, 155-165. 
Yönetim ve Ekonomi Araștırmalarl Dergisi / Journal of Management and Economics Research

Cilt/Volume: 19 Sayl/Issue: 4 Arallk/December 2021 ss. /pp. 404-418

E. Akdamar, M. Göğebakan http://dx.doi.org/10.11611/yead.996572

Andreou, P. C., Louca, C., \& Panayides, P. M. (2014). Corporate governance, financial management decisions and firm performance: Evidence from the maritime industry. Transportation Research Part E, 59-78.

Charbaji, H. F. (1994). APPLYING FACTOR ANALYSIS TO FINANCIAL RATIOS OF INTERNATIONAL COMMERCIAL AIRLINES. International Journal of Commerce and Management, 25-37.

Chen, K. H., \& Shimerda, T. A. (1981). An Empirical Analysis of Useful Financial Ratios. Financial Management, 51-60.

Corbett, J., \& Winebrake, J. (2008). The Impacts of Globalisation on International Maritime Transport Activity Past trends and future perspectives. Guadalajara: OECD.

De, A., \& Bandyopadhyay, G. (2011). Application of Factor Analysis on the Financial Ratios of Indian Cement Industry and Validation of the Results by Cluster Analysis. Journal of Business Studies Quarterly, 13-31.

Erdogan, A. I. (2013). Applying Factor Analysis on the Financial Ratios of Turkey's Top 500 Industrial Enterprises. International Journal of Business and Management, 134-139.

Gökçe, C. (2014). AVRUPA BİRLİĞİ VE TÜRKIYYE İÇİN ENERJİ KIRILGANLIK ENDEKSLERİ. Akademik Araştırmalar ve Çalışmalar Dergisi, 56-71.

Hamamcı, E. D., \& Şahinoğlu, T. (2020). Temel Bileşenler Analiziyle Yükselen Piyasa Ekonomilerinin Makroekonomik Performans1. Journal of Yasar University, 728-745.

Işı̆̆ıçok, E. (1999). Bursa'daki 100 Büyük Tekstil Firmasnın Temel Bileşenler Çözümlemesine göre Belirlenmesi. Öneri, 127-138.

Johnson, R., \& Wichern, D. (2002). Applied Multivariate Statistical Analysis. Saddle River: NJ: Prentice Hall.

Kang, H.-W., Wang, G. W., Bang, H.-S., \& Woo, S.-H. (2016). Economic performance and corporate financial management of shipping firms. Maritime Economics \& Logistics, 317-330.

Lee, P. T.-W., \& Lin, C.-W. (2014). The cognition map of financial ratios of shipping companies using DEMATEL and MMDE. Maritime Policy \& Management: The flagship journal of international shipping and port research, 133-145.

Lee, P. T.-W., Lin, C.-W., \& Chung, Y.-S. (2014). Comparison analysis for subjective and objective weights of financial positions of container shipping companies. Maritime Policy \& Management: The flagship journal of international shipping and port research, 241-250. 
Yönetim ve Ekonomi Araștırmalarl Dergisi / Journal of Management and Economics Research

Cilt/Volume: 19 Sayl/Issue: 4 Arallk/December 2021 ss. /pp. 404-418

E. Akdamar, M. Göğebakan http://dx.doi.org/10.11611/yead.996572

Lee, P. T.-W., Lin, C.-W., \& Shin, S.-H. (2012). A comparative study on financial positions of shipping companies in Taiwan and Korea using entropy and grey relation analysis. Expert Systems with Applications, 5649-5657.

Martí, L., Martín, J. C., \& Puertas, R. (2017). A Dea-Logistics Performance Index. Journal of Applied Economics, 169-192.

Öcal, M. E., Oral, E. L., Erdis, E., \& Vural, G. (2007). Industry financial ratios—application of factor analysis in Turkish construction industry. Building and Environment, 385-392.

Özdamar, K. (2002). Paket Programları İle İstatistiksel Veri Analizi- 2 . Eskiş̧ehir: Kaan Kitapevi.

Özdamar, K. (2004). Paket Programlar Ille İstatistiksel Veri Analizi. Eskişehir: Kaan Kitabevi.

Özdamar, K., \& Dinçer, K. (1987). Bilgisayarla istatistik değerlendirme ve veri analizi. İstanbul: Bilim Teknik Kitabevi.

Pantouvakis, A., \& Dimas, A. (2010). Does ISO 9000 series certification matter for the financial performance of ports? Some preliminary findings from Europe. Maritime Policy \& Management: The flagship journal of international shipping and port research, 505-522.

Pinches, G. E., Mingo, K. A., \& Caruthers, J. K. (1973). THE STABILITY OF FINANCIAL PATTERNS IN INDUSTRIAL ORGANIZATIONS. The Journal of Finance, 389-396.

Servi, T., \& Erişoğlu, Ü. (2020). Türkiye'deki Şehirlerin Sosyo-Ekonomik Gelişmişlik Düzeylerinin İstatistiksel Analizi. Al-Farabi International Journal on Social Sciences, 174-186.

Syriopoulos, T., \& Tsatsaronis, M. (2011). The corporate governance model of the shipping firms: financial performance implications. Maritime Policy \& Management: The flagship journal of international shipping and port research, 585-604.

Tabachnick, B., Fidell, L., \& Ullman, J. (2007). Using multivariate statistics . Boston: MA: Pearson.

WSJ. (2020, Ocak 5). WSJ. https://www.wsj.com/market-data/quotes/company-list/sector/watertransport shipping adresinden alındı

Yong, A. G., \& Pearce, S. (2013). A Beginner's Guide to Factor Analysis: Focusing on Exploratory Factor Analysis. Tutorials in Quantitative Methods for Psychology, 79-94. 


\begin{tabular}{|c|c|c|}
\hline $\begin{array}{c}\text { KATKI ORANI / } \\
\text { CONTRIBUTION RATE }\end{array}$ & $\begin{array}{l}\text { AÇIKLAMA / } \\
\text { EXPLANATION }\end{array}$ & $\begin{array}{c}\text { KATKIDA } \\
\text { BULUNANLAR / } \\
\text { CONTRIBUTORS }\end{array}$ \\
\hline $\begin{array}{c}\text { Fikir veya Kavram / Idea } \\
\text { or Notion }\end{array}$ & $\begin{array}{l}\text { Araştırma hipotezini veya } \\
\text { fikrini oluşturmak / Form the } \\
\text { research hypothesis or idea }\end{array}$ & $\begin{array}{l}\text { Dr. Öğr. Üyesi Emrah } \\
\text { AKDAMAR } \\
\text { Dr. Öğr. Üyesi Maruf } \\
\text { GÖGEBAKAN }\end{array}$ \\
\hline Tasarım / Design & $\begin{array}{l}\text { Yöntemi, ölçeği ve deseni } \\
\text { tasarlamak / Designing } \\
\text { method, scale and pattern }\end{array}$ & $\begin{array}{l}\text { Dr. Öğr. Üyesi Emrah } \\
\text { AKDAMAR } \\
\text { Dr. Öğr. Üyesi Maruf } \\
\text { GÖGEBAKAN } \\
\end{array}$ \\
\hline $\begin{array}{c}\text { Veri Toplama ve İşleme / } \\
\text { Data Collecting and } \\
\text { Processing }\end{array}$ & $\begin{array}{c}\text { Verileri toplamak, } \\
\text { düzenlenmek ve raporlamak / } \\
\text { Collecting, organizing and } \\
\text { reporting data }\end{array}$ & $\begin{array}{l}\text { Dr. Öğr. Üyesi Emrah } \\
\text { AKDAMAR } \\
\text { Dr. Öğr. Üyesi Maruf } \\
\text { GÖGEBAKAN }\end{array}$ \\
\hline $\begin{array}{l}\text { Tartişma ve Yorum / } \\
\text { Discussion and } \\
\text { Interpretation }\end{array}$ & $\begin{array}{c}\text { Bulguların } \\
\text { değerlendirilmesinde ve } \\
\text { sonuçlandırılmasında } \\
\text { sorumluluk almak / Taking } \\
\text { responsibility in evaluating } \\
\text { and finalizing the findings }\end{array}$ & $\begin{array}{l}\text { Dr. Öğr. Üyesi Emrah } \\
\text { AKDAMAR } \\
\text { Dr. Öğr. Üyesi Maruf } \\
\quad \text { GÖGEBAKAN }\end{array}$ \\
\hline $\begin{array}{l}\text { Literatür Taraması / } \\
\text { Literature Review }\end{array}$ & $\begin{array}{c}\text { Çalışma için gerekli literatürü } \\
\text { taramak / Review the literature } \\
\text { required for the study }\end{array}$ & $\begin{array}{l}\text { Dr. Öğr. Üyesi Emrah } \\
\text { AKDAMAR } \\
\text { Dr. Öğr. Üyesi Maruf } \\
\text { GÖGEBAKAN }\end{array}$ \\
\hline
\end{tabular}

Hakem Değerlendirmesi: Dış bağımsız.

Çıkar Çatışması: Yazarlarçıkar çatışması bildirmemiştir.

Finansal Destek: Yazarlar bu çalışma için finansal destek almadığını beyan etmiştir.

Teşekkür: -

Peer-review: Externally peer-reviewed.

Conflict of Interest: The authors have no conflict of interest to declare.

Grant Support: The authors declared that this study has received no financial support.

Acknowledgement: - 